\title{
Laparoscopic management of Peutz-Jeghers syndrome (PJS) presenting with chronic non-ischaemic jejuno-jejunal intussusception in an adolescent girl
}

\author{
Ramnik V Patel, ${ }^{1,2}$ Michael Stanton, ${ }^{3}$ Joseph Curry, ${ }_{1}^{4}$ Edward Kiely ${ }^{4}$
}

'Department of Paediatric Urology, University College London Hospitals NHS Foundation Trust, London, UK ${ }^{2}$ Department of Paediatric, Great Ormond Street Children Hospital NHS Trust, London, UK

${ }^{3}$ Southampton General Hospital, Southampton, UK ${ }^{4}$ Specialist Neonatal and Paediatric Surgery (SNAPS) Department, Great Ormond Street Hospital, London, UK

Correspondence to Ramnik V Patel, ramnik@doctors.org.uk
To cite: Patel RV, Stanton M, Curry J, et al BMJ Case Rep Published online: [please include Day Month Year] doi:10.1136/ bcr-2013-200939

\section{DESCRIPTION}

A 13-year-old girl presented with intermittent upper abdominal pain and vomiting over the duration of 9 months. The physical examination showed pigmentation on the perioral region with upper abdominal fullness and tenderness over left flank. She had iron deficiency anaemia. An abdominal ultrasound scan (USS) showed evidence of nonischaemic chronic jejuno-jejunal intussusception (figure 1C-E). An upper gastrointestinal contrast study showed dilated duodenal loops and irregularity of bowel in the mid abdomen (figure 1A,B, arrows). During laparoscopy, a large polyp forming the lead point of the intussusceptum in the proximal jejunum was found. Reduction of intussception, segmental resection of the jejunum containing polyps, resection of the remaining polyps after prolapsing the proximal and distal limbs of the proximal jejunum and primary anastomosis were performed extracorporeally. The histopathological examination showed hamartoma, confirming the diagnosis of Peutz-Jeghers syndrome (PJS). Her postoperative course was uneventful. She had one colonic and one rectal polyp resected during annual surveillance endoscopies (oesophago-gastroduodenoscopy, ileo-colonoscopy and video capsule endoscopy) in the following 2 years. She is fit and asymptomatic at 5 years follow-up. PJS is an unusual autosomal dominant disease, characterised by gastrointestinal polyposis associated with mucocutaneous pigmentation and increased risk of gastrointestinal and extra-gastrointestinal malignancies. Chronic non-ischaemic intussusception could be the presenting feature of the PJS. ${ }^{1-3}$ Intussusception, on USS, may present the characteristic 'target' or 'doughnut' signs in cross-sectional images and the 'telescope' or 'pseudo-kidney' signs in longitudinal images. Many surveillance recommendation

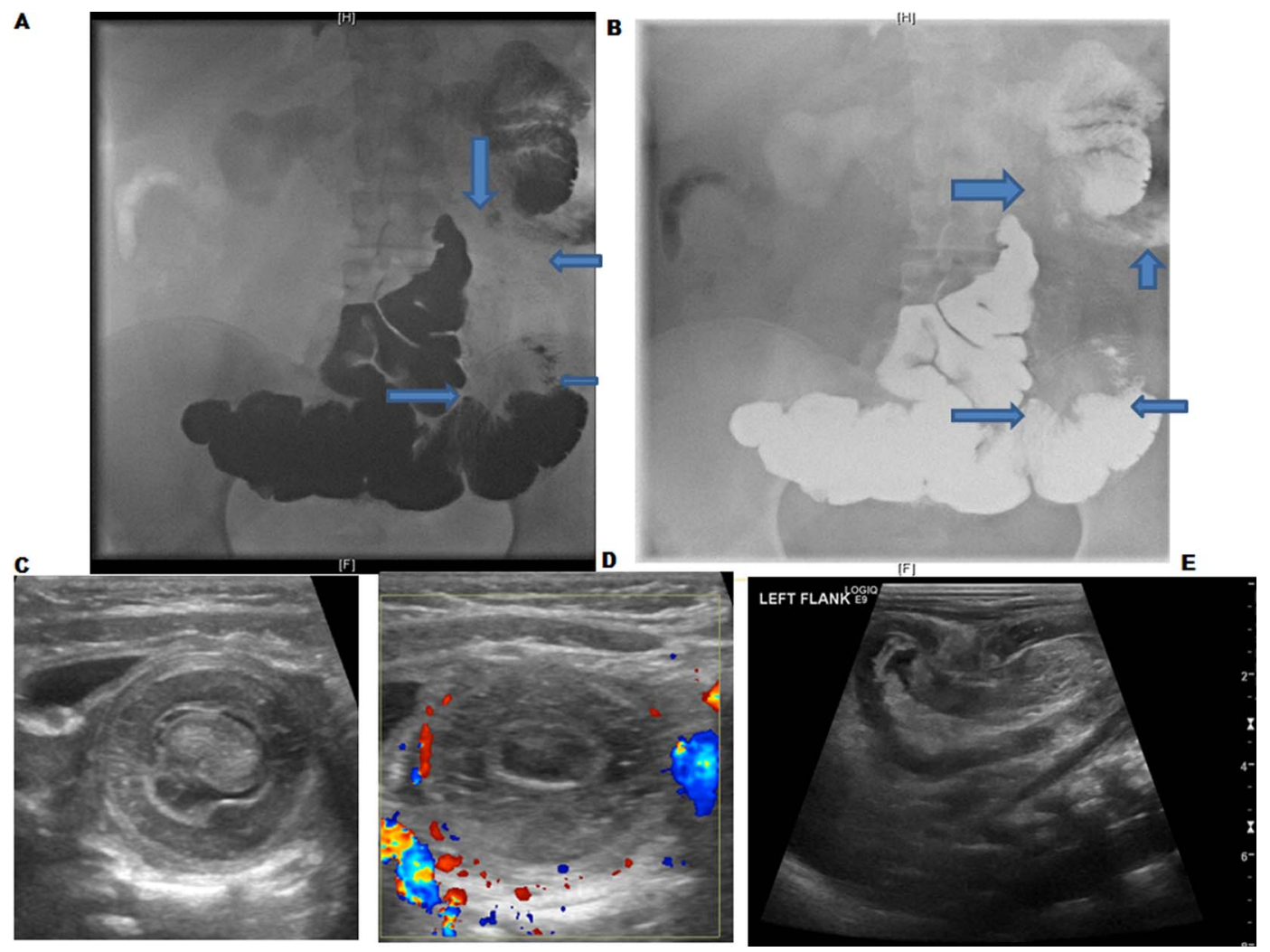

Figure 1 ( $A$ and $B$ ) Upper gastrointestinal contrast study showing dilated duodenum and proximal jejunum with filling defect and mass effect in the proximal jejunum (arrows). (C-E) Ultrasound scan and colour Doppler study showing classic target/doughnut sign on cross-section and pseudo-kidney/telescope sign on longitudinal scan image and good vascularity on the colour Doppler study. 
strategies have been in place for gastrointestinal polyps/malignancies and other neoplasias.

\section{Learning points}

Family history and perioral examination for mucocutaneous pigmentation may be rewarding in chronic abdominal pain and vomiting as our patient was labelled as abdominal migraine and cyclical vomiting.

- Ultrasound scan is diagnostic of intussusception and colour Doppler shows the vascularity and MRI scan or gastrointestinal contrast study or endoscopy with capsule video-endoscopy is helpful in finding remaining polyps.

- There are non-surgical options for diagnosis, reduction of intussusception and resection of the polyp should be considered whenever possible and feasible.
Contributors All authors have actively participated in the preparation of the manuscript, editing and finalizing this manuscript.

Competing interests None.

Patient consent Obtained.

Provenance and peer review Not commissioned; externally peer reviewed.

\section{REFERENCES}

1 Hokama A, Inamine M, Kishimoto $K$, et al. Telescope sign of intussusception in Peutz-Jeghers syndrome. Dig Liver Dis 2010;42:153.

2 Miura Y, Yamamoto H, Sunada K, et al. Reduction of ileoileal intussusception by using double-balloon endoscopy in Peutz-Jeghers syndrome (with video). Gastrointest Endosc 2010;72:658-9.

3 Burton MJ, Seery JP, Taylor-Robinson SD, et al. Jejunal intussusception secondary to Peutz-Jeghers type hamartoma diagnosed on angiography. Clin Radiol 1999;54:476-8.

Copyright 2013 BMJ Publishing Group. All rights reserved. For permission to reuse any of this content visit http://group.bmj.com/group/rights-licensing/permissions.

BMJ Case Report Fellows may re-use this article for personal use and teaching without any further permission.

Become a Fellow of BMJ Case Reports today and you can:

- Submit as many cases as you like

- Enjoy fast sympathetic peer review and rapid publication of accepted articles

- Access all the published articles

- Re-use any of the published material for personal use and teaching without further permission

For information on Institutional Fellowships contact consortiasales@bmjgroup.com

Visit casereports.bmj.com for more articles like this and to become a Fellow 